\title{
Managing conflict in aquaculture
}

\author{
Keith W. Hipel \\ Department of Systems Design Engineering, University of Waterloo, \\ Waterloo, Canada; \\ Centre for International Governance Innovation, \\ Waterloo, Canada and \\ Balsillie School of International Affairs, Waterloo, Canada \\ Liping Fang \\ Department of Mechanical and Industrial Engineering, Ryerson University, \\ Toronto, Canada and \\ Department of Systems Design Engineering, University of Waterloo, \\ Waterloo, Canada, and \\ Yi Xiao \\ Department of Systems Design Engineering, University of Waterloo, \\ Waterloo, Canada
}

\begin{abstract}
Purpose - A flexible decision technology called the Graph Model for Conflict Resolution (GMCR) is applied to a generic aquaculture conflict to illustrate how GMCR can be used to systematically investigate a wide range of conflicts arising in aquaculture in order to obtain meaningful strategic insights and thereby assist in making informed decisions in aquaculture development. To emphasize the importance of being able to resolve aquaculture controversies, a review of the global economic impacts of the aquaculture industry is provided and the key stakeholders who may be involved in aquaculture disputes along with their legitimate interests are identified. The paper aims to discuss these issues.

Design/methodology/approach - The GMCR methodology comprises two main stages: modeling and analysis. During the modeling stage, key decision makers (DMs), the options under each DM's control and each DM's relative preferences over feasible states are identified based on a thorough background investigation to a given dispute. Within the analysis stage, solution concepts that describe key characteristics of human behavior under conflict are utilized to determine resolutions that could occur when DMs interact under pure competition and cooperatively. Interpretation of the equilibrium results provides meaningful strategic insights for better understanding which strategies a given DM could select as the conflict evolves over time.

Findings - The results demonstrate how difficult it can be to balance the interests of different key stakeholders in aquaculture development. In all possible resolutions identified in the generic aquaculture conflict, at least two DMs among First Nations, environmental group and residents (Res) would object to the expansion of aquaculture activities due to the assumption that the government would choose to appease one stakeholder at a time. They also reflect the need for a useful tool box of decision technologies for addressing the vast range of challenges that could arise in the important area of marine economics and management.

Originality/value - The GMCR methodology possesses several unique and key original capabilities in comparison to other conflict analysis models. First, it only requires limited information to calibrate a conflict model. Second, it contains a number of solution concepts that describe how a DM could think and behave under conflict. Third, it furnishes a range of informative output, follow-up analyses and advice for use in
\end{abstract}

(C) Keith W. Hipel, Liping Fang and Yi Xiao. Published in Marine Economics and Management. Published by Emerald Publishing Limited. This article is published under the Creative Commons Attribution (CC BY 4.0) licence. Anyone may reproduce, distribute, translate and create derivative works of this article (for both commercial and non-commercial purposes), subject to full attribution to the original publication and authors. The full terms of this licence may be seen at http://creative commons.org/licences/by/4.0/legalcode

The authors appreciate receiving funding provided by two Discovery Grants from the Natural Sciences and Engineering Research Council (NSERC) of Canada.

Managing conflict in aquaculture

Received 4 June 2018 Accepted 4 June 2018 
MAEM

1,1

real-life decision support. Finally, all of the foregoing advantages of GMCR can be contained within decision support systems that permit practitioners and researchers to readily apply the GMCR methodology to real-life conflicts.

Keywords Aquaculture, Conflict, Graph Model for Conflict Resolution, Strategic insights

Paper type Research paper

\section{Introduction}

The vast resources of the oceans are essential for the survival and welfare of humanity around the globe. It is not surprising, therefore, that economic activities connected to our oceans, such as maritime transportation and fisheries, are greatly expanding within a highly competitive environment among nations and other interest groups. With respect to transportation, for example, the oceans provide natural "water highways" for facilitating trade on a massive scale among the nations of the world using large cargo ships and oil tankers. In fact, the number of ships and amount of cargo being shipped around the globe are increasing dramatically (UNCTAD, 2017, Table 1.3 and Figure 1.2), and key shipping lanes like the Straits of Malacca and the Panama Canal are crowded with ships. Moreover, the oceans provide a huge sink for absorbing greenhouse gases like carbon dioxide which mitigates damage to climate system but causes a rise in ocean acidity which in turn has detrimental effects upon coral reefs and other sea life. As mentioned later in this paper, the oceans furnish a valuable food supply for society both from the natural harvesting of the ocean's sea life and seaweed as well as via fish farming or aquaculture.

Due to the aforesaid and many other reasons, our valuable ocean resources must be properly utilized, developed and managed in a sustainable and fair way which account for the legitimate interests of the different stakeholders. Accordingly, the timely journal entitled "Marine Economics and Management (MAEM)" is being launched to directly address issues connected to the responsible utilization of our oceans for the benefit of society in combination with minimization of harm to the natural environment. Important topics which this journal will address include: planning and management of the marine economy and industry, marine economic policy analysis and evaluation, marine resources and rights management, marine economic security and monitoring, marine disasters associated with the greatly increasing utilization of the oceans' precious resources, landsea economic coordination and proper balance between the development of the economy and environment.

Informative decision technologies from the fields of economics, management, operations research, systems engineering and elsewhere will be needed to assist in addressing many important issues connected to the management of our indispensable marine resources. For instance, optimization techniques are commonly utilized to find the best strategy for producing a maximum economic return or achieving minimum cost to accomplish a task (Björndal et al, 2004; Arnason, 2009). Multiple criteria decision analysis tools can be very useful when a fishery company is deciding whether or not to invest more resources to expand its operations in a number of possible ways according to a range of economic, environmental and societal criteria (El-Gayar and Leung, 2001; Halmar et al., 2009; Estévez and Gelcich, 2015).

Because conflict often arises among competing interest groups involved in a given marine economic activity, such as aquaculture expansion, decision tools for handling conflict have a key role to play in marine economics and management. Within this paper, the Graph Model for Conflict Resolution (GMCR) (Kilgour et al., 1987; Fang et al., 1993; Xu et al., 2018) will be introduced and illustrated for resolving a real-life dispute arising over aquaculture development in the Province of British Columbia (BC), Canada. However, an overview of aquaculture development around the globe is firstly presented. Then, some typical controversies that could take place along with the rapid expansion of aquaculture 
are explained. Subsequently, how an aquaculture conflict can be resolved and how GMCR can be applied to solve a real-world aquaculture dispute are described in detail. Several meaningful findings and recommendations are put forward in the last section.

\section{Worldwide perspective}

Aquaculture, or fish farming is globally considered as one of the fastest growing food-producing sectors, currently providing about half of the fishery products consumed by humans, as reported by the Food and Agriculture Organization (FAO) and as displayed in Figure 1 (FAO, 2018). In contrast to wild fishing, which exhibited a stable trend in total production, aquaculture's contribution in food fish has almost quadrupled, from 13 to 45 percent, during the past two and half decades, as indicated in Figure 1.

The most recent statistics released by the FAO in March 2017 reported the highest production record of all time, with a total global quantity of $106 \mathrm{~m}$ tonnes, having an estimated value of $\$ 163 \mathrm{bn}$ in the year of 2015 , as indicated by the data on the far-right in Figure 2. This total output mainly consists of food fish, aquatic plants and non-food products like pearls. As can be seen from the figure, the total quantity of aquaculture production in 2015 is approximately 2.5 times that in 2000, and 6.3 times that in 1990. The estimated value of aquaculture production increased by 320 percent between 2000 and 2015, and by 610 percent between 1990 and 2015. Among the total production, more than half of it comes from the marine sector as shown by the darker black bars in Figure 2, while production from the inland sector, indicated by the lighter gray bars in the figure, increased rapidly during the past few decades.

All of the data mentioned above and displayed in Figures 1 and 2 demonstrate that products from aquaculture are playing an increasingly important role in meeting the growing demand for food on a worldwide basis. This expanding output also poses a range of new challenges, such as how society can achieve sustainable aquaculture development. Because of the great impact of this crucial food source, controversies in aquaculture become unavoidable among a range of competing stakeholder groups having greatly differing interests.

\section{Controversies in aquaculture}

This rapid expansion of aquaculture has provided significant benefits to some groups within this industry. Indeed, the aquaculture industry not only produced billions of dollars

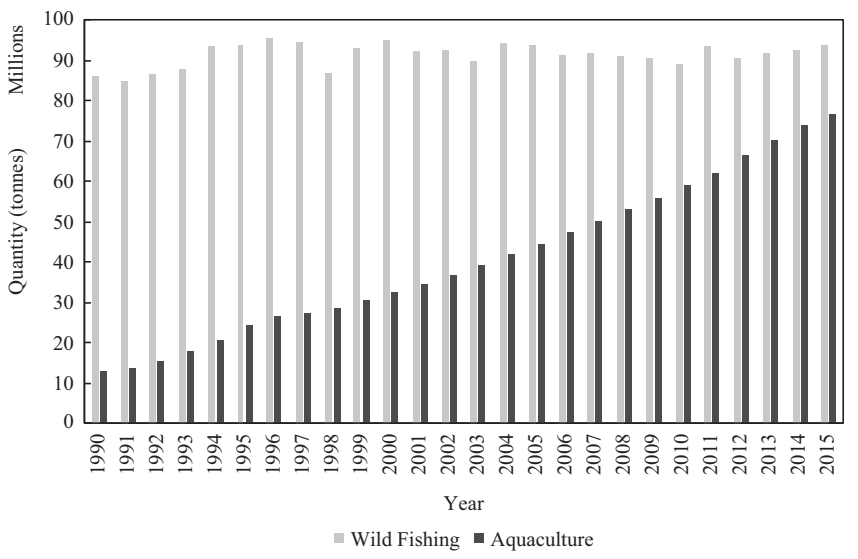

Source: FAO (2018) Fishstat Plus Database, version 2.3

Managing conflict in aquaculture

Figure 1.

Comparison of global production from wild fishing and aquaculture 


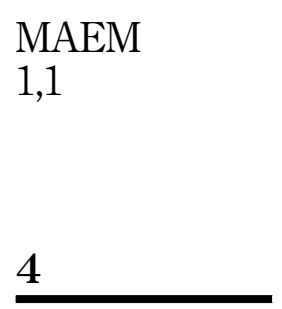

Figure 2.

Global aquaculture production in quantity and total value

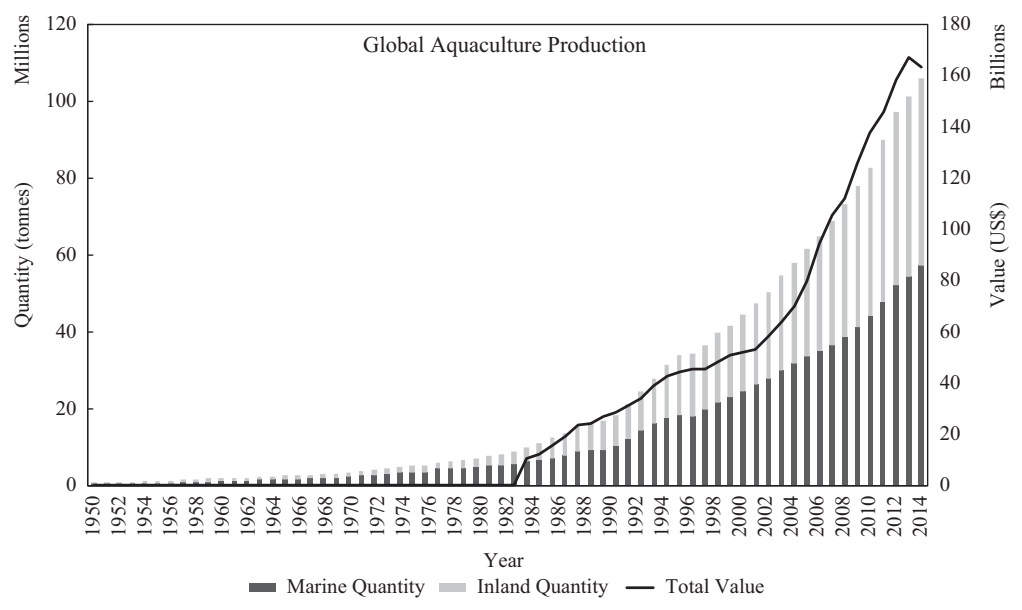

Source: FAO (2018) Fishstat Plus Database, version 2.3

in economic returns, but also created millions of jobs. Naturally, there are many supporters for a further expansion of aquaculture. However, this growth also brings with it numerous concerns to other stakeholders, such as residents depending on the natural aquatic environment for their livelihoods or environmentalists who worry about pollution caused by aquaculture facilities. It is not surprising, therefore, that conflicts inevitably arise among the different kinds of stakeholders having diverse self-interests as to what should be done with respect to aquaculture.

In general, the most obvious and generic kind of aquaculture conflict occurs between supporters and opponents of aquaculture development. Aquaculture companies and their workers are obviously considered as supporters of aquaculture expansion. In fact, even within the supporters, there exists fierce competition among different companies since each of them independently attempts to enlarge its share of the market. Sometimes a company, for instance, may purposefully lower its price in order to gain a greater market share, or a small company may launch lawsuits against large corporations for competing unfairly.

On the opponents' side, environmentalists are often against aquaculture expansion because of the potentially negative ecological impacts. For instance, foreign fish species may be raised at various locations because of the huge potential economic profits. However, the foreign species could possibly cause a biological disaster for native local fish populations via the introduction of new disease strains to which local fish are not immune. Furthermore, mixing of species may bring about a devastating catastrophe for the ecosystem at some places (Gozlan et al., 2010). Local residents and First Nation (FN) (indigenous) groups may also be involved in a conflict when they are adversely affected by aquaculture activities. Moreover, the wild fishing sector may react aggressively toward the rapid expansion of aquaculture, since this expansion can adversely impact its benefits by capturing a greater market share and significantly decreasing average prices.

Governments or administrative agencies are normally responsible for monitoring, regulating and managing the development of aquaculture. Conflicts may arise between governments and aquaculture companies when, for example, a governmental regulating agency discovers that a company is secretly releasing untreated wastes directly into the environment. Moreover, often within different levels of government, priorities may be different over aquaculture development and environmental protection. In many nations, the central or federal government would emphasize the importance of preserving ecosystems 
while developing aquaculture, and there would normally exist guidelines for aquaculture development and environmental protection. However, some local governments may prefer economic benefits and job opportunities over environmental protection, and thus encourage a large expansion of the aquaculture industry. In this case, conflict could also take place between the central or federal government and local governments. Nations could also end up in a dispute when, for instance, one country concludes that its natural resources are being polluted by aquaculture development in its neighboring nations, or one disagrees with another regarding the proper management of shared coastal aquaculture resources.

In addition to the various forms of conflicts mentioned above, there are many other kinds of controversies that could occur among different stakeholders. All of these types of conflicts need to be handled very carefully so that disputes can be peacefully resolved and perhaps a win/win resolution can be achieved rather than a zero-sum situation in which one party's gain is another participant's loss.

\section{Conflict resolution in aquaculture}

As just mentioned, conflicts in aquaculture could arise for many reasons, ranging from simple to complex ones such as environmental disputes, commercial competition or some combination thereof. The various types of conflict possess different characteristics depending on the specific subject and involved stakeholders, since each stakeholder might have different objectives or values regarding the conflict. In order to resolve the different conflicts considering diverse stakeholders' values, a comprehensive yet flexible decision technology is required.

The GMCR constitutes a powerful technique for finding possible resolutions to conflict situations involving many different stakeholders having various types of interests and behavioral characteristics (Kilgour et al., 1987; Fang et al., 1993; Xu et al., 2018). Strategic insights can be obtained from utilizing GMCR to assist in making informed decisions within a conflict environment. In fact, the GMCR methodology has been widely applied to solve conflicts in a number of areas including aquaculture. Noakes et al. (2005) discussed the negotiations over the Pacific salmon treaties between the USA and Canada, and examined the stability of treaties using GMCR. Their GMCR investigations permitted them to discover why the 1985 treaty was not stable but a revised treaty in 1999 could bring about a win/win solution for both countries. The west coast of Canada has a long history of fish farming and has experienced speedy growth during the past few decades. Concerns from the local residents and indigenous people have made the $\mathrm{BC}$ government take action. For example, a moratorium on salmon farming expansion was posed in 1995 by the government. The Environmental Assessment Office carried out a study and provided 49 recommendations for the sustainable development of the salmon farming industry. This dispute was examined by Noakes et al. (2003) using GMCR. In 2001, an Action Plan was initiated by the $\mathrm{BC}$ government to address concerns of local communities regarding the development of the shellfish industry at Baynes Sound, which Hamouda et al. (2004) investigated in-depth using GMCR. Hamouda et al. (2005) proposed a generic aquaculture dispute that involves many stakeholders within the conflict. The main findings of the generic conflict are discussed in detail in the next section to illustrate how GMCR works in practice and can provide valuable strategic insights for making more informed decisions.

\section{GMCR in aquaculture management}

In this section, the application of the GMCR to a generic aquaculture conflict is presented. An overview of the GMCR, including its main components, key advantages and applications, is firstly discussed. Subsequently, how it can be employed in practice is explained step by step using the generic aquaculture conflict.

\section{Managing conflict in aquaculture}


MAEM

1,1

\subsection{Overview of the GMCR}

Since the 1940s, a rich range of formal decision models have been developed for enhancing and supporting the decision-making process. As explained by authors such as $\mathrm{Xu}$ et al. (2018, Chapter 2), Hipel (2009), Hipel, Kilgour, Rajabi and Chen (2009) and Fang et al. (1993, Chapter 1), many of these decision technologies have been designed within the fields of operations research and systems engineering. Game theory constitutes an important class of decision models, which were specifically constructed for addressing various decision situations in which multiple participants or stakeholders having different multiple objectives are in dispute over some issues such as pollution caused by aquaculture activities. A methodology which is particularly constructed for addressing complex conflicts is the GMCR (Kilgour et al., 1987; Fang et al., 1993; Xu et al., 2018), which constitutes a significant expansion of its predecessors: metagame analysis (Howard, 1971) and conflict analysis (Fraser and Hipel, 1979, 1984). As mentioned in the previous section, GMCR has been successfully applied to aquaculture disputes. Other fields in which GMCR has been utilized include brownfields (Hu et al., 2009; Bernath Walker et al., 2010; Hipel, Hegazy and Yousefi, 2010; Yousefi et al., 2010c, 2011; Hipel and Bernath Walker, 2012; Philpot et al., 2017), construction management (Kassab et al., 2006, 2010, 2011; Yousefi et al., 2010a, b), energy (Armin et al., 2012; Matbouli et al., 2015; Xiao et al., 2015; Garcia et al., 2016; O'Brien and Hipel, 2016), indigenous people relations (Ma et al., 2005; Obeidi et al., 2006), military science (Fraser et al., 1990; Kilgour et al., 1998; Hipel, 2011; Hipel et al., 2014), trade (Hipel et al., 1990, 2001) and sustainable development (Levy et al., 1995; Hipel and Obeidi, 2005; Ghanbarpour and Hipel, 2009).

The GMCR methodology is purposefully designed to investigate real-world conflicts in order to obtain meaningful insights to satisfactorily resolve a given dispute by meeting each stakeholder's interests as much as possible within the social constraints of a given problem and possibly even reaching a win/win resolution. GMCR possesses several unique and key advantages in comparison to other conflict analysis models. First, it only needs limited information to calibrate a conflict model. The basic input information required for modeling purposes includes: decision makers (DMs) and their options (courses of actions) in the conflict, and their relative preferences over all possible feasible states. Second, it contains a number of solution concepts, also called stability definitions, that describe how a DM would think and behave under conflict. These solution concepts capture key characteristics of various types of human behavior such as how foresighted a DM can think in terms of potential moves and countermoves, whether or not a DM has knowledge of other DMs' preferences, and does a DM accept strategic risk. Third, it furnishes a range of informative output, follow-up analyses and advice for use in real-life decision support. Finally, all of the foregoing advantages of GMCR can be contained within decision support systems (DSSs) that permit practitioners and researchers to readily apply the GMCR methodology to real-life conflicts. A universal design for a DSS for GMCR is provided by Xu et al. (2018, Chapter 10) while some DSSs for GMCR are available for employment now, such as GMCR II (Hipel et al., 1997; Fang et al., 2003a, b) and GMCR+ (Kinsara et al., 2015).

The GMCR methodology consists of two stages: modeling and analysis, as indicated in Figure 3. In the modeling phase, basic information such as DMs and their options are first input, and then a set of states is formed based on which options are selected by the DMs controlling them. Subsequently, a ranking of all of the feasible states for each DM is determined by using a number of means like preference statements or weights. This ranking of states is called the preference or preference ranking for a DM. To construct the preference for a DM, only relative information is required. For instance, it is only necessary to know if a person prefers coffee to tea, but not by how much. Also, the DM may not care whether or not she receives coffee or tea if they are equally preferred.

In the analysis stage, using the above input data one can determine which states are stable for a DM according to various stability definitions or solution concepts. Commonly 


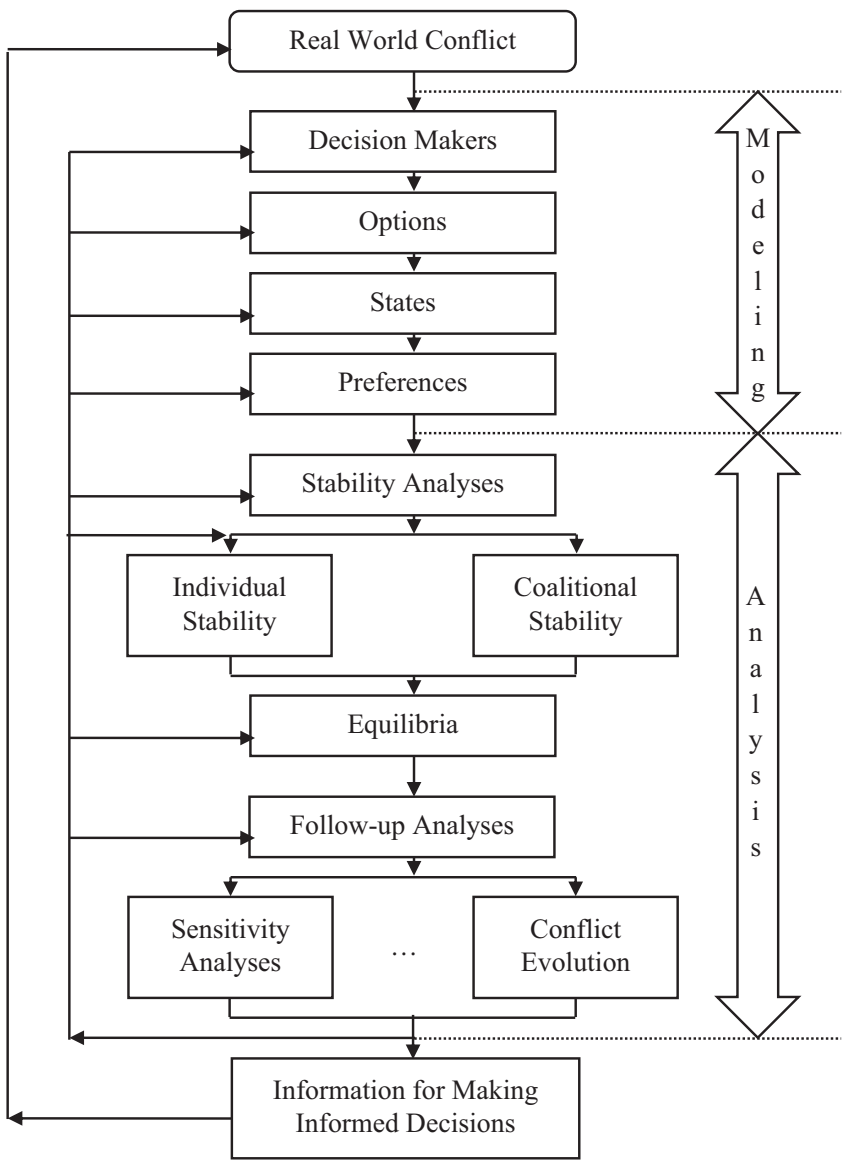

Managing conflict in aquaculture

Source: Based on Xu et al. (2018)

Figure 3.

Main components of the graph model for conflict resolution methodology

used solution concepts include: Nash stability (R) (Nash, 1950, 1951), general metarationality (GMR) (Howard, 1971), symmetric metarationality (SMR) (Howard, 1971), sequential stability (SEQ) (Fraser and Hipel, 1979, 1984), limited-move $\left(L_{h}\right)$ (Kilgour et al., 1987) and Non-myopic (NM) (Kilgour et al., 1987). A state is stable for a DM under a particular stability definition if the DM has no incentive to move away from this state. A state is called an equilibrium or a possible resolution when it is stable for all of the DMs under a particular solution concept. Moreover, one can also examine whether or not a DM can cooperate with others to achieve a better outcome using what is referred to as coalitional stability analysis. One can further ascertain the robustness of the equilibria by carrying out sensitivity analyses. One can also track the evolution of the conflict over time. A last but not least step is to interpret the meaning of the outcomes in the real-life situation in order to decide what strategic actions can be taken by a DM in order to fare as well as possible within the strategic constraints of the dispute under study.

In addition to the main components shown in Figure 3, the GMCR methodology has been greatly expanded during the last decade for handling more complex and realistic conflicts. For instance, preference uncertainty is an inherent and important characteristic of many 
MAEM

1,1

conflict situations in the real world. Therefore, advances to represent uncertainty are made in terms of fuzzy (Al-Mutairi et al., 2008a, b; Hipel et al., 2011; Bashar et al., 2012, 2014, 2015, 2016, 2018), grey (Kuang, Bashar, Hipel and Kilgour, 2015; Kuang, Bashar, Kilgour and Hipel, 2015; Zhao and Xu, 2017), probabilistic (Rego and dos Santos, 2015; Silva et al., 2017), and unknown preferences (Li et al., 2004; Yu et al., 2016), and combinations of the above preferences. Psychological factors could have significant impact on decision-making processes. Consequently, some of them, such as attitudes (Inohara et al., 2007; Bernath Walker et al., 2009, 2012a, b; Yousefi et al., 2010a, b, c), emotions (Obeidi et al., 2005, 2009a, b) and misperceptions (Takahashi et al., 1984; Hipel et al., 1988; Wang et al., 1988, 1989; Wang and Hipel, 2009; Aljefri et al., 2014, 2016, 2018) are also examined within the paradigm of GMCR.

\subsection{Aquaculture dispute}

To demonstrate how GMCR can be utilized to solve conflicts in aquaculture, an illustrative case study with respect to an environmental dispute in BC, Canada, is presented next. Environmental controversy commonly arises in aquaculture in which a group of people such as environmentalists or residents are against a proposed aquaculture expansion, which may be supported by government for economic reasons as long as it is environmentally sound.

5.2.1 DMs and options. In this conflict model, five DMs are identified: aquaculture industry and its supporters (AIS), First Nations (FN), environmental groups (EG), residents (Res) and government (Gov). The aquaculture industry considers itself to be an essential contributor to food supply and economic development in $\mathrm{BC}$, Canada, and is requesting further expansion. This request is also supported by some other interest groups for economic development, such as fish processing and shipping corporations. Since the aquaculture industry and its supporters have the same interests regarding expansion, they are considered as one DM (called AIS) in this conflict. This DM has essentially four options under its control: request new expansion opportunities; respect FN rights and take actions to reduce threats to FN rights; adopt advanced technical measures to mitigate potential environmental impacts of aquaculture expansion; and avoid conflicts with local stakeholders in areas of common resources development opportunities.

FN are concerned about the potential threats to their land, water and other resources as well as their way of life. Since aboriginal rights are protected by the Douglas Treaties in BC, which states that the FN control their land entirely and forever and can carry on fisheries as formerly, the FN can initiate legal actions under applicable treaties against aquaculture expansion when they fear expansion may endanger their rights (Gerwing and McDaniels, 2006; Joyce and Satterfield, 2010).

Many EG have expressed their concerns with respect to the environmental risks brought by aquaculture expansion such as new diseases and waste discharges. They are worried that the aquaculture industry may not be as responsible and sustainable as declared, and could cause devastating damage to the environment. Moreover, some of the risks are irreversible or far more expensive to restore once a negative consequence is realized such as the spread of a foreign disease from farmed fish among naturally occurring fish. To counteract these risks, the EG can start legal actions under the Fisheries Act to protect the environment.

Residents (Res) depending on marine/coastal environment are another stakeholder who may rally against aquaculture expansion, as their livelihoods and well-being might be negatively affected by the expansion. When they have such concerns, they can choose to oppose the expansion by means of appeals to politicians or media campaigns.

The DM called government (Gov) represents federal and provincial governments and other responsible administrative agencies who view aquaculture expansion in essentially 
the same way. This DM plays an important role in resolving an aquaculture conflict, since it is responsible for regulating and managing aquaculture development and it holds the power to approve or reject an expansion request from the aquaculture industry. In this case, there exist several options for this DM: approve expansion requests, which certainly would promote economic growth and create job opportunities; suspend aquaculture where aboriginal rights may be affected, since FN rights are considered as a sensitive political issue in $\mathrm{BC}$; impose a moratorium on further aquaculture development and consult with an advisory panel to obtain recommendations; and reduce the scale of aquaculture in areas of conflict to appease the opposition of local stakeholders.

A summary of the key DMs and their options is listed in Table I. It should be noted that, to a large degree, some DMs may not be involved in the conflict in some situations. Then one can remove these DMs from the model and re-analyze the conflict. All possible DMs are included in this paper in order to gain insights on a broad front.

Because each option can be chosen or not, a conflict model with 11 options contains a total of $2^{11}=2,048$ mathematically possible states. But not all of them are feasible in practice. The GMCR methodology provides several ways to conveniently remove the infeasible states according to informative categories and thereby reduce the size of the mathematical model of the conflict: mutually exclusive, which means that at most one option can be selected among a specified set of options controlled by a DM, at least one, which stands for the scenarios in which at least one option must be chosen since the DM under consideration is expected to take some type of action and option dependence, which indicates that one option can be taken only when some other options are already taken or not. In this aquaculture conflict model, it is assumed that AIS's four options are mutually exclusive and at least one must be chosen, and Gov's four options are mutually exclusive. An example of option dependence is that if AIS requests new expansion, all of FN, EG and Res do not take legal actions or oppose, then Gov may choose to make no choice. As a consequence, the number of possible states is reduced from 2,048 to 129 feasible states after removing the infeasibilities. Moreover, it is assumed that Gov's moves are irreversible, which means its actions cannot be undone once it makes a decision to take certain actions.

5.2.2 Preferences. As aforementioned, GMCR only requires relative preference information to construct preference ranking of states for each DM where ties are allowed. GMCR provides several approaches to specify the ranking or ordering of states: option prioritizing, in which a list of hierarchical logical preference statements about options or combination of options is used to express a DM's preferences, by employing various logical connectives such as and (\&), or (I), if, and iff (if and only if); option weighting, in which all states are ranked by assigning weights to the options to represent the importance of each

\begin{tabular}{|c|c|c|}
\hline DMs & Options & Option labels \\
\hline \multirow{4}{*}{$\begin{array}{l}\text { Aquaculture industry and } \\
\text { its supporters (AIS) }\end{array}$} & 1. Request new expansion opportunities & Request \\
\hline & 2. Respect FN rights and take actions to reduce threats & Respect \\
\hline & $\begin{array}{l}\text { 3. Mitigate potential environmental impacts by adopting } \\
\text { technical measures }\end{array}$ & Mitigate \\
\hline & 4. Avoid conflict with local stakeholders in areas of conflict & Avoid \\
\hline First Nations (FN) & 5. Initiate legal actions to protect their resources and way of life & Initiate \\
\hline Environmental groups (EG) & 6. Start legal actions under Fisheries Act & Legal \\
\hline Residents (Res) & 7. Oppose expansion in areas of conflict & Oppose \\
\hline \multirow{4}{*}{ Governments (Gov) } & 8. Approve aquaculture expansion requests & Approve \\
\hline & 9. Suspend aquaculture where aboriginal rights apply & Suspend \\
\hline & 10. Impose moratorium on further development & Moratorium \\
\hline & 11. Reduce aquaculture in areas of conflict & Reduce \\
\hline
\end{tabular}

\section{Managing conflict in aquaculture}

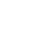


MAEM

1,1

10

option for a given DM and then summing across the options to get a ranking for each state for which a higher number means more preferred; and direct specification by ordering the states by hand from most to least preferred.

For the aquaculture application, option prioritizing method is utilized to obtain a ranking of states separately for each DM. Table II presents a list of preference statements for the EG listed from most important at the top to least important at the bottom in terms of option numbers. The right column contains an English explanation as to what each statement means. For instance, option 3 (AIS chooses to mitigate potential environmental risks by adopting advanced technology) is the most important preference statement for EG, and therefore appears at the top of the list. The second most preferred preference statement for EG is -6 iff 3, which stands for EG prefers option 6 not to be selected (a negative sign means that the option is not taken and legal actions in not initiated against aquaculture expansion) if and only if option 3 is taken (environmental risks are mitigated). However, if necessary technology is not selected by AIS, then EG would start legal actions to prevent further aquaculture expansion (6 iff -3), as indicated in the third preference statement. Notice that all of these hierarchical preference statements closely reflect the way DMs may voice their preferences when speaking with others. Assuming transitive preferences, a simple algorithm uses the hierarchical preference statements to rank the states from most to least preferred where equally preferred sets of states are permitted.

A list of the preference statements for each DM from most preferred on the top to least preferred at the bottom is shown in Table III. By using these statements, a ranking of states for each DM from most preferred to least preferred can be determined using the algorithm

Statements Interpretations

$3 \quad$ EG most prefers that AIS takes advanced technology to mitigate environmental risks (option 3 is selected)

-6 iff 3 EG would not like to start legal actions if and only if AIS selects to mitigate environmental risks (option 6 is not taken iff option 3 is chosen)

6 iff $-3 \quad$ EG prefers to start legal actions if and only if AIS selects not to mitigate environmental risks (option 6 is taken iff option 3 is not chosen)

Table II. $\quad 10 \quad$ EG would like the Gov chooses to impose moratorium on further development

statements for the $\quad 9 / 11 \quad$ EG equally prefers that Gov selects to suspend or reduce aquaculture

environmental $\quad 8 \quad$ EG then would like the Gov chooses to approve aquaculture expansion requests

groups (EG) $\quad 517 \quad$ EG equally prefers that FN and Res take actions to oppose aquaculture expansion

Table III. $\quad-6$

\begin{tabular}{lcccc}
\hline AIS & FN & EG & Res & Gov \\
\hline 8 & 2 & 3 & 4 & $8|9| 10111$ \\
-9 & -5 iff 2 & -6 iff 3 & -7 iff 4 & $-8|-9|-10 \mid-11$ \\
-10 & 5 iff -2 & 6 iff -3 & 7 iff -4 & \\
-11 & 9 & 10 & 11 & \\
1 iff $8 \mid(-5 \&-6 \&-7)$ & 10111 & 9111 & 9110 & \\
-5 & 8 & 8 & 8 & \\
-6 & 617 & 517 & 516 &
\end{tabular}

Summary of option $\quad-7$ prioritizing statements 2 iff 5

in aquaculture $\quad 3$ iff 6

conflict model $\quad 4$ iff 7 
just mentioned. Because there is a total of 129 feasible states, the ranking of states for each of the five DMs is not provided here.

5.2.3 Individual stability analysis. In this phase, calculations are carried out for determining stability of every state for each DM under each solution concept. The solution concepts used in the calculation and their corresponding description are provided in Table IV. With the assistance of DSSs like GMCR II or GMCR+, the individual stability and equilibria results can be conveniently obtained. In fact, 19 states are identified to be equilibria under at least one of the solution concepts listed in Table IV. Among them, nine states are transitional noncooperative equilibria for which equilibrium jumps may occur (Kilgour et al., 2001). In an equilibrium jump, DMs in a coalition can cooperate by jointly moving from one noncooperative equilibrium to another one which is more preferred by all coalition members to the one from which they moved. Therefore, these states are not considered as final potential resolutions, but will be further analyzed in coalitional stability analyses. The remaining ten equilibria states are listed in Table $\mathrm{V}$ and examined here.

As can be seen in Table V, the top part lists the option form for each equilibrium, in which a "Y" means an option is selected by the DM controlling that option, and an "N"

\begin{tabular}{ll}
\hline Solution concepts & Descriptions \\
\hline $\begin{array}{l}\text { Nash stability (R) } \\
\text { General metarationality (GMR) }\end{array}$ & $\begin{array}{l}\text { Focal DM has no unilateral improvements } \\
\text { All of focal DM's unilateral improvements are sanctioned by } \\
\text { opponents' moves }\end{array}$ \\
Symmetric metarationality (SMR) & $\begin{array}{l}\text { All of focal DM's unilateral improvements are sanctioned by opponents' } \\
\text { moves, even after focal DM takes one more move }\end{array}$ \\
Sequential stability (SEQ) & $\begin{array}{l}\text { All of focal DM's unilateral improvements are sanctioned by opponents' } \\
\text { unilateral improvements }\end{array}$ \\
Limited-move stability $\left(L_{h}\right)(h>0)$ & $\begin{array}{l}\text { All DMs act optimally for up to } h \text { steps } \\
\text { Limiting case of limited-move stability as } h \text { increases to infinity }\end{array}$
\end{tabular}

Managing conflict in aquaculture

\begin{tabular}{|c|c|c|c|c|c|c|c|c|c|c|c|c|}
\hline DMs & Option labels & & & & & & & & & & & \\
\hline \multirow[t]{4}{*}{ AIS } & 1. Request & $\mathrm{Y}$ & $\mathrm{N}$ & $\mathrm{N}$ & $\mathrm{N}$ & $\mathrm{N}$ & $\mathrm{N}$ & $\mathrm{N}$ & $\mathrm{N}$ & $\mathrm{N}$ & $\mathrm{N}$ & \\
\hline & 2. Respect & $\mathrm{N}$ & $\mathrm{N}$ & $\mathrm{N}$ & $\mathrm{Y}$ & $\mathrm{N}$ & $\mathrm{N}$ & $\mathrm{Y}$ & $\mathrm{N}$ & $\mathrm{N}$ & $\mathrm{Y}$ & \\
\hline & 3. Mitigate & $\mathrm{N}$ & $\mathrm{N}$ & $\mathrm{Y}$ & $\mathrm{N}$ & $\mathrm{N}$ & $\mathrm{Y}$ & $\mathrm{N}$ & $\mathrm{N}$ & $\mathrm{Y}$ & $\mathrm{N}$ & \\
\hline & 4. Avoid & $\mathrm{N}$ & $\mathrm{Y}$ & $\mathrm{N}$ & $\mathrm{N}$ & $\mathrm{Y}$ & $\mathrm{N}$ & $\mathrm{N}$ & $\mathrm{Y}$ & $\mathrm{N}$ & $\mathrm{N}$ & \\
\hline $\mathrm{FN}$ & 5. Initiate & $\mathrm{Y}$ & $\mathrm{Y}$ & $\mathrm{Y}$ & $\mathrm{N}$ & $\mathrm{Y}$ & $\mathrm{Y}$ & $\mathrm{N}$ & $\mathrm{Y}$ & $\mathrm{Y}$ & $\mathrm{N}$ & \\
\hline EG & 6. Legal & $\mathrm{Y}$ & $\mathrm{Y}$ & $\mathrm{N}$ & $\mathrm{Y}$ & $\mathrm{Y}$ & $\mathrm{N}$ & $\mathrm{Y}$ & $\mathrm{Y}$ & $\mathrm{N}$ & $\mathrm{Y}$ & \\
\hline Res & 7. Oppose & $\mathrm{Y}$ & $\mathrm{N}$ & $\mathrm{N}$ & $\mathrm{Y}$ & $\mathrm{N}$ & $\mathrm{Y}$ & $\mathrm{Y}$ & $\mathrm{N}$ & $\mathrm{Y}$ & $\mathrm{Y}$ & \\
\hline \multirow{4}{*}{ Gov } & 8. Approve & $\mathrm{Y}$ & $\mathrm{N}$ & $\mathrm{N}$ & $\mathrm{N}$ & $\mathrm{N}$ & $\mathrm{N}$ & $\mathrm{N}$ & $\mathrm{N}$ & $\mathrm{N}$ & $\mathrm{N}$ & \\
\hline & 9. Suspend & $\mathrm{N}$ & $\mathrm{Y}$ & $\mathrm{Y}$ & $\mathrm{Y}$ & $\mathrm{N}$ & $\mathrm{N}$ & $\mathrm{N}$ & $\mathrm{N}$ & $\mathrm{N}$ & $\mathrm{N}$ & \\
\hline & 10. Moratorium & $\mathrm{N}$ & $\mathrm{N}$ & $\mathrm{N}$ & $\mathrm{N}$ & $\mathrm{Y}$ & $\mathrm{Y}$ & $\mathrm{Y}$ & $\mathrm{N}$ & $\mathrm{N}$ & $\mathrm{N}$ & \\
\hline & 11. Reduce & $\mathrm{N}$ & $\mathrm{N}$ & $\mathrm{N}$ & $\mathrm{N}$ & $\mathrm{N}$ & $\mathrm{N}$ & $\mathrm{N}$ & $\mathrm{Y}$ & $\mathrm{Y}$ & $\mathrm{Y}$ & \\
\hline State number & & 30 & 49 & 56 & 59 & 81 & 88 & 91 & 113 & 120 & 123 & \\
\hline \multirow[t]{6}{*}{ Solution concepts } & $\operatorname{Nash}(R)$ & $\nu$ & & & & & & & & & & \\
\hline & GMR & レ & $\nu$ & $\nu$ & $\nu$ & レ & $\nu$ & $\nu$ & レ & レ & レ & \\
\hline & SMR & レ & $\nu$ & $\nu$ & $\nu$ & 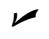 & $\nu$ & $\nu$ & レ & レ & レ & \\
\hline & SEQ & レ & $\nu$ & $\nu$ & 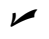 & レ & $\nu$ & $\nu$ & レ & レ & レ & \\
\hline & $L_{h}(h \geqslant 2)$ & & $\nu$ & $\nu$ & $\nu$ & レ & $\nu$ & $\nu$ & レ & レ & レ & \\
\hline & NM & レ & $\nu$ & $\nu$ & $\nu$ & レ & $\nu$ & $\nu$ & $\nu$ & $\nu$ & $\nu$ & Table V. \\
\hline AIS option & & 1 & 4 & 3 & 2 & 4 & 3 & 2 & 4 & 3 & 2 & Equilibria states and \\
\hline Gov option & & 8 & 9 & 9 & 9 & 10 & 10 & 10 & 11 & 11 & 11 & their option form \\
\hline
\end{tabular}


MAEM

1,1

12

stands for the option is not taken. For example, state 30 is expressed as (YNNN, Y, Y, Y, YNNN) in option form. It represents that the first option controlled by the AIS is chosen but the other three are not. Then the FN, EG and Res all select their options, respectively, and the Gov takes the first option under its control. The bottom part of Table V shows the solution concepts under which each equilibrium is determined. All of the equilibrium states satisfy the solution concepts GMR, SMR, SEQ, $L_{h}(h \geqslant 2)$ and NM, and state 30 is also Nash stable. State 30 indicates that AIS requests further expansion and the governments approve its request. This combination of selections, of course, incurs opposition from the other three DMs. However, it seems these three DMs could not make the situation to transit to another state despite their strong desire to be against the expansion.

The remaining nine equilibria in Table $\mathrm{V}$ can actually be categorized into three groups according to different perspectives. First, consider the categorization based on the actions of AIS. States 49, 81 and 113 can be potential resolutions when AIS chooses to avoid conflict with DMs in areas of conflict, which means that AIS will act to appease the local residents. Therefore, Res would not raise opposition while the FN and EG both take legal actions no matter what Gov selects. When AIS prefers to appease the EG by adopting advanced technical measures to mitigate potential environmental risks, states 56, 88 and 120 are most likely to take place. In these three states, the EG will be satisfied and do not start legal action, and the FN and Res both object the expansion. When AIS acts to accommodate the FN, then the FN will do nothing but the EG and Res would not be happy. This is what happened in states 59, 91 and 123 .

From another viewpoint, depending on the option selected by the government as shown in the last row of Table $\mathrm{V}$, these nine equilibria can be categorized into three new groups. If the Gov prefers option 9, it means that aboriginal rights are first supported by the government. Therefore, states 49, 56 and 59 can be considered as a group. Within this group, it is easy to observe that if AIS acts to appease the residents, then the Res will do nothing, while if AIS chooses to adopt advanced technology to satisfy the EG, then the EG will not take legal actions. It is very similar for the other two groups when the Gov selects option 10 and 11 , respectively.

When the two perspectives are combined, it can be concluded that among these nine equilibria states 59, 88 and 113 are most likely to happen, because the choices of AIS and Gov coincide. For instance, in state 59 both AIS and Gov select to address the primary concern of FN.

5.2.4 Coalitional stability analysis. As mentioned in the previous section, nine other equilibria are transitional noncooperative equilibria (states 63, 64, 65, 95, 96, 97, 127, 128 and 129). These nine states are not considered as final potential resolutions because an equilibrium jump may occur. For example, as explained in Table VI, state 63 (NYNN, Y, Y, Y, NYNN) is

Table VI.

Evolution from a transitional equilibrium to a coalitional equilibrium

\begin{tabular}{|c|c|c|}
\hline DMs and options & Transitional equilibrium & Coalitional equilibrium \\
\hline \multicolumn{3}{|l|}{ AIS } \\
\hline 1. Request & $\mathrm{N}$ & $\mathrm{N}$ \\
\hline 2. Respect & $\mathrm{Y}$ & $\rightarrow \mathrm{N}$ \\
\hline 3. Mitigate & $\mathrm{N}$ & $\mathrm{N}$ \\
\hline 4. Avoid & $\mathrm{N}$ & $\rightarrow \mathrm{Y}$ \\
\hline \multicolumn{3}{|l|}{ FN } \\
\hline 5. Initiate & $\mathrm{Y}$ & $\mathrm{Y}$ \\
\hline \multicolumn{3}{|l|}{ EG } \\
\hline 6. Legal & $\mathrm{Y}$ & $\mathrm{Y}$ \\
\hline \multicolumn{3}{|l|}{ Res } \\
\hline 7. Oppose & $\mathrm{Y}$ & $\longrightarrow \mathrm{N}$ \\
\hline \multicolumn{3}{|l|}{ Gov } \\
\hline 8. Approve & $\mathrm{N}$ & $\mathrm{N}$ \\
\hline 9. Suspend & $\mathrm{Y}$ & $\mathrm{Y}$ \\
\hline 10. Moratorium & $\mathrm{N}$ & $\mathrm{N}$ \\
\hline 11. Reduce & $\mathrm{N}$ & $\mathrm{N}$ \\
\hline State number & 63 & 49 \\
\hline
\end{tabular}


one transitional equilibrium, in which AIS selects to respect aboriginal rights but the FN still initiate legal actions. Then AIS would change its action and turn to form a coalition with the Res and reach a bilateral agreement, and the equilibrium will jump to state 49 (NNNY, Y, Y, N, NYNN), making state 63 unstable. In fact, each of the nine transitional equilibria can jump to one of the equilibria listed in Table V. Moreover, one can carry out a full coalitional study by further examining every state for coalitional stability using a set of coalitional solution concepts formally defined by Inohara and Hipel (2008a, b) and Zhu et al. (2018).

5.2.5 Evolution of the conflict. After examining both individual and coalitional stability, one may wish to consider executing appropriate follow-up analyses, as indicated near the bottom of Figure 3. As an important component of the follow-up analyses, evolution of a conflict examines how a conflict evolves from the current situation (also referred to as the status quo) to potential final equilibria. Identifying the possible paths is useful to understand how each DM behaves during each step. Figure 4 displays the potential evolution of the conflict under the scenario that the Gov selects to suspend aquaculture where aboriginal rights may be affected. As can be seen from the figure, each DM's selection of option is listed below the corresponding state number. Under the current situation, AIS is requesting new expansion opportunities, and other DMs have not taken any actions. When the Gov decides to support the FN people, aquaculture would be suspended where aboriginal rights may be affected, thereby option 9 (suspend) is selected and state 34 is reached. If the EG takes the next step and chooses to initiate legal actions under Fisheries Act, the conflict moves to state 42 . Then the AIS would change its decision and select to respect the aboriginal rights, and the conflict evolves to state 43 . From state 43, the FN would do nothing since the AIS selects to appease its concerns, while the Res would oppose the expansion, which makes the conflict move to state 59. As indicated in previous section, state 59 is one of the equilibria in which no DM has incentive to move away from it. This evolution is shown at the top branch of Figure 4.

If the FN takes action before the EG does, then the conflict will move to state 38 . Depending on the choices of AIS, there exist two possible states: state 41 if AIS chooses to avoid conflict and state 40 if AIS selects to mitigate potential environmental risks. State 49 would be the final equilibrium for the former case, and state 56 is the resolution for the latter situation.

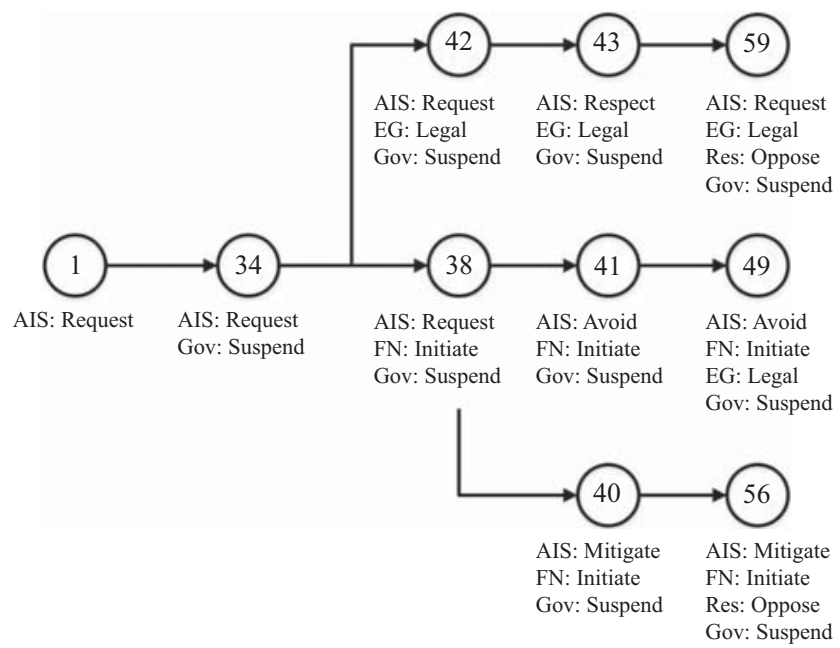

Managing conflict in aquaculture

13
Figure 4.

Potential evolution of the conflict under the scenario of the Gov chooses to suspend aquaculture where aboriginal rights may be affected 
MAEM

1,1

Based on the stability results in terms of both individual stability and coalitional stability and the evolution of this generic aquaculture conflict, it can be concluded that the AIS and Gov are two main determinants of the results. It is very likely that when the government makes a decision, the AIS would respond and comply with the policy selected by the government. In all possible resolutions, at least two DMs among FN, EG and Res would object to the expansion due to the assumption that the government would choose to appease one stakeholder at a time. It seems to be very difficult to balance the interests of different stakeholders. Moreover, in all possible resolutions, if AIS decides to satisfy the interests of one stakeholder group, then that group will likely be satisfied with the outcome and not be against the expansion. The findings also suggest one situation in which the government prefers economic growth to environment and approves new expansion requests regardless of the opposition of many stakeholders.

\section{Conclusions and opportunities}

The aquaculture dispute systematically investigated in this paper demonstrates that GMCR can provide valuable strategic insights for enhancing the decision-making process. The authors believe that GMCR methodology should prove to be highly effective in resolving conflict in the many areas in which controversies could take place in the broad field of Marine Economics and Management. Overall, difficult problems that arise in this field should inspire the utilization, improvement and development of many types of decision tools. In fact, a key motivation for originally creating GMCR was to design and construct a decision methodology having the capability to address challenging decision situations occurring in water resources and environmental management. One should keep in mind that Sir Isaac Newton developed the mathematics of calculus so he could properly describe his laws of physics in which rate of change was a key factor to be able to explain mathematically. Likewise, the journal of Marine Economics and Management has the potential to be a useful outlet for not only tackling tough practical problems using an array of existing tools but also one in which new decision methodologies are expanded and built. Hence, the journal provides an attractive platform for developing new and improved decision technologies for addressing pressing marine problems, and disseminating these ideas globally.

One should keep in mind that the vast array of challenges happening within the marine domain is highly interconnected. For instance, marine disasters, such as large oil spills and the deliberate dumping of wastes by coastal cities and ships into the oceans, can significantly affect fishing which in turn has detrimental economic and environmental consequences. Therefore, it can be instructive to envision reality in terms of a system of systems engineering perspective as suggested by authors such as Hipel, Obeidi, Fang and Kilgour (2009), Hipel, Fang and Heng (2010) and Xu et al. (2018, Chapter 2). Management and governance of our marine resources should be integrative, by accounting for interconnections among systems, and adaptive in order to be able to respond to emerging properties or surprises that could burst forth in complex systems involving our oceans. Moreover, as illustrated in the aquaculture dispute studied in this paper, the value systems or preferences of the key stakeholder groups should be taken into account. In this way, fairness, robustness, sustainability and other key desirable systems characteristics will be maintained.

\section{References}

Aljefri, Y.M., Fang, L. and Hipel, K.W. (2014), "Modeling misperception of options and preferences in the graph model for conflict resolution", Proceedings of the 2014 IEEE International Conference on Systems, Man and Cybernetics, San Diego, CA, pp. 1573-1578, doi: 0.1109/SMC.2014.6974140.

Aljefri, Y.M., Bashar, M.A., Fang, L. and Hipel, K.W. (2018), "First level hypergame for investigating misperception in conflicts", IEEE Transactions on Systems, Man, and Cybernetics: Systems, 18pp., doi: 10.1109/TSMC.2017.2690619. 
Aljefri, Y.M., Hipel, K.W., Fang, L. and Bashar, M.A. (2016), "Misperception in nationalization of the Suez Canal", Proceedings of the 2016 IEEE International Conference on Systems, Man and Cybernetics, Budapest, pp. 355-360, DOI: 10.1109, doi: /SMC.2016.7844266.

Al-Mutairi, M.S., Hipel, K.W. and Kamel, M.S. (2008a), "Fuzzy preferences in conflicts", Journal of Systems Science and Systems Engineering, Vol. 17 No. 3, pp. 257-276, doi: 10.1007/s115 18-008-5088-4.

Al-Mutairi, M.S., Hipel, K.W. and Kamel, M.S. (2008b), "Trust and cooperation from a fuzzy perspective", Mathematics and Computers in Simulation, Vol. 76 Nos 5/6, pp. 430-446, doi: 10.1016/j.matcom.2007.04.006.

Armin, M., Hipel, K.W. and De, M. (2012), "The Ontario nuclear power dispute: a strategic analysis", Environmental Systems Research, Vol. 1 No. 11, pp. 1-16, doi: 10.1186/2193-2697-1-11.

Arnason, R. (2009), "Fisheries management and operations research", European Journal of Operational Research, Vol. 193 No. 3, pp. 741-751, doi: 10.1016/j.ejor.2007.07.028.

Bashar, M.A., Kilgour, D.M. and Hipel, K.W. (2012), "Fuzzy preferences in the graph model for conflict resolution”, IEEE Transactions on Fuzzy Systems, Vol. 20 No. 4, pp. 760-770, doi: 10.1109/ TFUZZ.2012.2183603.

Bashar, M.A., Kilgour, D.M. and Hipel, K.W. (2014), "Fuzzy option prioritization for the graph model for conflict resolution”, Fuzzy Sets and Systems, Vol. 246, pp. 34-48, doi: 10.1016/j.fss.2014.02.11.

Bashar, M.A., Hipel, K.W., Kilgour, D.M. and Obeidi, A. (2015), "Coalition fuzzy stability analysis in the graph model for conflict resolution”, Journal of Intelligent and Fuzzy Systems, Vol. 29 No. 2, pp. 593-607, doi: 10.3233/IFS-141336.

Bashar, M.A., Hipel, K.W., Kilgour, D.M. and Obeidi, A. (2018), "Interval fuzzy preferences in the graph model for conflict resolution", Fuzzy Optimization and Decision Making, Vol. 17 No. 3, pp. 287-315, doi: 10.1007/s10700-017-9279-7.

Bashar, M.A., Obeidi, A., Kilgour, D.M. and Hipel, K.W. (2016), "Modeling Fuzzy and interval fuzzy preferences within a graph model framework", IEEE Transactions on Fuzzy Systems, Vol. 24 No. 4, pp. 765-778, doi: 10.1109/TFUZZ.2015.2446536.

Bernath Walker, S., Boutilier, T. and Hipel, K.W. (2010), "Systems management study of a private brownfield renovation", Journal of Urban Planning and Development, Vol. 136 No. 3, pp. 249-260, doi: 10.1061/(ASCE)0733-9488(2010)136:3(249).

Bernath Walker, S., Hipel, K.W. and Inohara, T. (2009), "Strategic decision making for improved environmental security: coalitions and attitudes in the graph model for conflict resolution", Journal of Systems Science and Systems Engineering, Vol. 18 No. 4, pp. 461-476, doi: 10.1007/ s11518-009-5119-9.

Bernath Walker, S., Hipel, K.W. and Inohara, T. (2012a), "Dominating attitudes in the graph model for conflict resolution", Journal of Systems Science and Systems Engineering, Vol. 21 No. 3, pp. 316-336, doi: 10.1007/s11518-012-5198-x.

Bernath Walker, S., Hipel, K.W. and Inohara, T. (2012b), "Attitudes and preferences: approaches to representing decision maker desires", Applied Mathematics and Computation, Vol. 218 No. 12, pp. 6637-6647, doi: 10.1016/j.amc.2011.11.102.

Björndal, T., Lane, D.E. and Weintraub, A. (2004), "Operational research models and the management of fisheries and aquaculture: a review”, European Journal of Operational Research, Vol. 156 No. 3, pp. 533-540, doi: 10.1016/S0377-2217(03)00107-3.

El-Gayar, O.F. and Leung, P. (2001), "A multiple criteria decision making framework for regional aquaculture development", European Journal of Operational Research, Vol. 133 No. 3, pp. 462-482, doi: 10.1016/S0377-2217(00)00183-1.

Estévez, R.A. and Gelcich, S. (2015), "Participative multi-criteria decision analysis in marine management and conservation: research progress and the challenge of integrating value judgments and uncertainty", Marine Policy, Vol. 61, pp. 1-7, doi: 10.1016/j.marpol.2015.06.022.

Fang, L., Hipel, K.W. and Kilgour, D.M. (1993), Interactive Decision Making: The Graph Model for Conflict Resolution, ISBN: 0-471-59237-4, Wiley, New York, NY, 221pp. 
MAEM

1,1

Fang, L., Hipel, K.W., Kilgour, D.M. and Peng, X. (2003a), "A decision support system for interactive decision making, part 1: model formulation”, IEEE Transactions on Systems, Man and Cybernetics, Part C: Applications and Reviews, Vol. 33 No. 1, pp. 42-55, doi: 10.1109/TSMCC.2003.809361.

Fang, L., Hipel, K.W., Kilgour, D.M. and Peng, X. (2003b), “A decision support system for interactive decision making, part 2: analysis and output interpretation”, IEEE Transactions on Systems, Man and Cybernetics, Part C: Applications and Reviews, Vol. 33 No. 1, pp. 56-66, doi: 10.1109/ TSMCC.2003.809360.

FAO (2018), "Fishstat plus database, version 2.3", Food and Agriculture Organization, April 7, Waterloo, available at: www.fao.org/fishery/statistics/en

Fraser, N.M. and Hipel, K.W. (1979), "Solving complex conflicts", IEEE Transactions on Systems, Man, and Cybernetics, Vol. 9 No. 12, pp. 805-816, doi: 10.1109/TSMC.1979.4310131.

Fraser, N.M. and Hipel, K.W. (1984), Conflict Analysis: Models and Resolutions, ISBN: 0-444-00921-3, North Holland, New York, NY, 377pp.

Fraser, N.M., Hipel, K.W., Jaworsky, J. and Zuljan, R. (1990), "A conflict analysis of the Armenian-Azerbaijani dispute”, The Journal of Conflict Resolution, Vol. 34 No. 4, pp. 652-677.

Garcia, A., Obeidi, A. and Hipel, K.W. (2016), "Two methodological perspectives on the energy east pipeline conflict”, Energy Policy, Vol. 91, pp. 397-409, doi: 10.1016/j.enpol.2016.01.033.

Gerwing, K. and McDaniels, T. (2006), "Listening to the salmon people: coastal first nations' objectives regarding salmon aquaculture in British Columbia”, Society and Natural Resources, Vol. 19 No. 3, pp. 259-273, doi: 10.1080/08941920500460864.

Ghanbarpour, M.R. and Hipel, K.W. (2009), "Sustainable development conflict over freeway construction”, Environment, Development and Sustainability, Vol. 11 No. 2, pp. 241-253, doi: 10.1007/s10668-007-9107-2.

Gozlan, R.E., Britton, J.R., Cowx, I. and Copp, G.H. (2010), "Current knowledge on non-native freshwater fish introductions”, Journal of Fish Biology, Vol. 76 No. 4, pp. 751-786, doi: 10.1111/j. 1095-8649.2010.02566.x.

Halmar, H., Stigebrandt, A., Rehbein, M. and McKinnon, A.D. (2009), "Developing a decision support system for sustainable cage aquaculture", Environmental Modelling \& Software, Vol. 24 No. 6, pp. 694-702, doi: 10.1016/j.envsoft.2008.10.013.

Hamouda, L., Hipel, K.W. and Kilgour, D.M. (2004), "Shellfish conflict in Baynes sound: a strategic perspective”, Environmental Management, Vol. 34 No. 4, pp. 474-486, doi: 10.1007/s00267-004-0227-2.

Hamouda, L., Hipel, K.W., Kilgour, D.M., Noakes, D.J., Fang, L. and McDaniels, T. (2005), "The salmon aquaculture conflict in British Columbia: a graph model analysis", Ocean and Coastal Management, Vol. 48 Nos 7/8, pp. 571-587, doi: 10.1016/j.ocecoaman.2005.02.001.

Hipel, K.W. (2009), "Formal models for conflict resolution and case studies", in Hipel, K.W. (Ed.), Topic Overview Paper, in Conflict Resolution, Encyclopedia of Life Support Systems (EOLSS), Vol. II, EOLSS Publishers, Oxford, pp. 86-122, available at: www.eolss.net

Hipel, K.W. (2011), "A systems engineering approach to conflict resolution in command and control", The International C2 Journal, Vol. 5 No. 1, pp. 1-56.

Hipel, K.W. and Bernath Walker, S. (2012), "Brownfield redevelopment”, in Craig, R.K., Pardy, B., Nagle, J.C., Schmitz, O. and Smith, W. (Eds), The Berkshire Encyclopedia of Sustainability, Volume 5 of 10 on Ecosystem Management and Sustainability, Berkshire Publishing, Barrington, MA, pp. 44-48.

Hipel, K.W. and Obeidi, A. (2005), "Trade versus the environment: strategic settlement from a systems engineering perspective”, Systems Engineering, Vol. 8 No. 3, pp. 211-233, doi: 10.1002/sys.20031.

Hipel, K.W., Dagnino, A. and Fraser, N.M. (1988), “A hypergame algorithm for modelling misperceptions in bargaining", Journal of Environmental Management, Vol. 27 No. 2, pp. 131-152.

Hipel, K.W., Fang, L. and Kilgour, D.M. (1990), “A formal analysis of the Canada - US softwood Lumber Dispute”, European Journal of Operational Research, Vol. 46 No. 2, pp. 235-246, doi: 10.1016/03772217(90)90134-W. 
Hipel, K.W., Hegazy, T. and Yousefi, S. (2010), "Combined strategic and tactical negotiation methodology for resolving complex brownfield conflicts", Pesquisa Operacional, Vol. 30 No. 2, pp. 281-304, doi: 10.1590/S0101-74382010000200003.

Hipel, K.W., Fang, L. and Heng, M. (2010), "System of systems approach to policy development for global food security”, Journal of Systems Science and Systems Engineering, Vol. 19 No. 1, pp. 1-21, doi: 10.1007/s11518-010-5122-1.

Hipel, K.W., Kilgour, D.M. and Bashar, M.A. (2011), "Fuzzy preferences in multiple participant decision making”, Scientia Iranica, Transactions D: Computer Science \& Engineering and Electrical Engineering, Vol. 18 No. 3 (D1), pp. 627-638, doi: 10.1016/j.scient.2011.04.016.

Hipel, K.W., Kilgour, D.M. and Kinsara, R.A. (2014), "Strategic investigations of water conflicts in the middle east", Group Decision and Negotiation, Vol. 23 No. 3, pp. 355-376, doi: 10.1007/s10726-012-9325-3.

Hipel, K.W., Kilgour, D.M., Fang, L. and Peng, X. (1997), "The decision support system GMCR in environmental conflict management", Applied Mathematics and Computation, Vol. 83 Nos 2/3, pp. 117-152, doi: 10.1016/S0096-3003(96)00170-1.

Hipel, K.W., Kilgour, D.M., Fang, L. and Peng, X. (2001), "Strategic decision support for the services industry", IEEE Transactions on Engineering Management, Vol. 48 No. 3, pp. 358-369, doi: $10.1109 / 17.946535$.

Hipel, K.W., Kilgour, D.M., Rajabi, S. and Chen, Y. (2009), "Chapter 27 - operations research and refinement of courses of action", in Sage, A.P. and Rouse, W.B. (Eds), Handbook of Systems Engineering and Management, 2nd ed., Wiley, New York, NY, pp. 1171-1222.

Hipel, K.W., Obeidi, A., Fang, L. and Kilgour, D.M. (2009), "Sustainable environmental management from a system of systems perspective", in Jamshidi, M. (Ed.), System of Systems Engineering: Innovations for the 21st Century, Chapter 18, Wiley, New York, NY, pp. 443-481.

Howard, N. (1971), Paradoxes of Rationality: Theory of Metagames and Political Behavior, MIT Press, Cambridge.

Hu, K., Hipel, K.W. and Fang, L. (2009), "A conflict model for the international hazardous waste disposal dispute”, Journal of Hazardous Materials, Vol. 172 No. 1, pp. 138-146, doi: 10.1016/j. jhazmat.2009.06.153.

Inohara, T. and Hipel, K.W. (2008a), "Coalition analysis in the graph model for conflict resolution", Systems Engineering, Vol. 11 No. 4, pp. 343-359, doi: 10.1002/sys.20104.

Inohara, T. and Hipel, K.W. (2008b), "Interrelationships among noncooperative and coalition stability concepts", Journal of Systems Science and Systems Engineering, Vol. 17 No. 1, pp. 1-29, doi: 10.1007/s11518-008-5070-1.

Inohara, T., Hipel, K.W. and Walker, S. (2007), "Conflict analysis approaches for investigating attitudes and misperceptions in the War of 1812", Journal of Systems Science and Systems Engineering, Vol. 16 No. 2, pp. 181-201, doi: 10.1007/s11518-007-5042-x.

Joyce, A.L. and Satterfield, T.A. (2010), "Shellfish aquaculture and first nations' sovereignty: the quest for sustainable development in contested sea space", Natural Resources Forum, Vol. 34 No. 2, pp. 106-123, doi: 10.1111/j.1477-8947.2010.01297.x.

Kassab, M., Hegazy, T. and Hipel, K.W. (2010), "Computerized decision support system for construction conflict resolution under uncertainty", Journal of Construction Engineering and Management, Vol. 136 No. 12, pp. 1249-1257, doi: 10.1061/(ASCE)CO.1943-7862.0000239.

Kassab, M., Hipel, K.W. and Hegazy, T. (2006), "Conflict resolution in construction disputes using the graph model", Journal of Construction Engineering and Management, Vol. 132 No. 10, pp. 1043-1052, doi: 10.1061/(ASCE)0733-9364(2006)132:10(1043).

Kassab, M., Hipel, K.W. and Hegazy, T. (2011), "Multi-criteria decision analysis for infrastructure privatization using conflict resolution", Structure and Infrastructure Engineering Maintenance, Management and Life-Cycle Design and Performance, Vol. 11 No. 9, pp. 661-671, doi: 10.1080/15732470802677649.

Kilgour, D.M., Hipel, K.W. and Fang, L. (1987), "The graph model for conflicts”, Automatica, Vol. 23 No. 1, pp. 41-55, doi: 10.1016/0005-1098(87)90117-8. 
MAEM

1,1

Kilgour, D.M., Hipel, K.W., Fang, L. and Peng, X. (2001), "Coalition analysis in group decision support”, Group Decision and Negotiation, Vol. 10 No. 2, pp. 159-175, doi: 10.1023/A:1008713120075.

Kilgour, D.M., Fang, L., Last, D., Hipel, K.W. and Peng, X. (1998), "Peace support, GMCR II, and Bosnia", in Woodcock, A.E.R. and Davis, D.F. (Eds), Analysis for Peace Operations, Canadian Peacekeeping Press, Clementsport, pp. 268-282.

Kinsara, R.A., Petersons, O., Hipel, K.W. and Kilgour, D.M. (2015), “Advanced decision support system for the graph model for conflict resolution”, Journal of Decision Systems, Vol. 24 No. 2, pp. 117-145, doi: 10.1080/12460125.2015.1046682.

Kuang, H., Bashar, M.A., Hipel, K.W. and Kilgour, D.M. (2015), "Grey-based preference in a graph model for conflict resolution with multiple decision makers", IEEE Transactions on Systems, Man and Cybernetics: Systems, Vol. 45 No. 9, pp. 1254-1267, doi: 10.1109/TSMC.2014.2387096.

Kuang, H., Bashar, M.A., Kilgour, D.M. and Hipel, K.W. (2015), "Strategic analysis of a brownfield revitalization conflict using the grey-based graph model for conflict resolution", EURO Journal on Decision Processes, Vol. 3 No. 3, pp. 219-248, doi: 10.1007/s40070-015-0042-4.

Levy, J.K., Hipel, K.W. and Kilgour, D.M. (1995), "A holistic approach to sustainable development: the graph model for conflict resolution", Information and Systems Engineering, Vol. 1, pp. 159-177.

Li, K.W., Hipel, K.W., Kilgour, D.M. and Fang, L. (2004), "Preference uncertainty in the graph model for conflict resolution", IEEE Transactions on Systems, Man, and Cybernetics, Part A, Systems and Humans, Vol. 34 No. 4, pp. 507-520, doi: 10.1109/TSMCA.2004.826282.

Ma, J., Hipel, K.W. and De, M. (2005), "Strategic analysis of the James Bay hydroelectric dispute in Canada”, Canadian Journal of Civil Engineering, Vol. 32 No. 5, pp. 868-880, doi: 10.1139/105-028.

Matbouli, Y., Hipel, K.W. and Kilgour, D.M. (2015), "Strategic analysis of the great Canadian hydroelectric power conflict", Energy Strategy Reviews, Vol. 4, pp. 43-51, doi: 10.1016/j.esr.2014.08.002.

Nash, J. (1950), "Equilibrium points in n-person games", Proceedings of the National Academy of Sciences of the United States of America, Vol. 36 No. 1, pp. 48-49, doi: 10.1073/pnas.36.1.48.

Nash, J. (1951), "Noncooperative games", Annals of Mathematics, Vol. 54 No. 2, pp. 286-295, doi: 10.1515/9781400884087-008.

Noakes, D.J., Fang, L., Hipel, K.W. and Kilgour, D.M. (2003), "An examination of the salmon aquaculture conflict in British Columbia using the graph model for conflict resolution", Fisheries Management and Ecology, Vol. 10 No. 3, pp. 123-137, doi: 10.1046/j.1365-2400.2003.00336.x.

Noakes, D.J., Fang, L., Hipel, K.W. and Kilgour, D.M. (2005), "The pacific salmon treaty: a century of debate and an uncertain future", Group Decision and Negotiation, Vol. 14 No. 6, pp. 501-522, doi: 10.1007/s10726-005-9005-7.

O'Brien, N.L. and Hipel, K.W. (2016), "A strategic analysis of the New Brunswick, Canada fracking controversy”, Energy Economics, Vol. 55, pp. 69-78, doi: 10.1016/j.eneco.2015.12.024.

Obeidi, A., Hipel, K.W. and Kilgour, D.M. (2005), "The role of emotions in envisioning outcomes in conflict analysis", Group Decision and Negotiation, Vol. 14 No. 6, pp. 481-500, doi: 10.1007/ s10726-005-9004-8.

Obeidi, A., Hipel, K.W. and Kilgour, D.M. (2006), "Turbulence in Miramichi Bay: the Burnt Church conflict over native fishing rights", Journal of the American Water Resources Association, Vol. 42 No. 12, pp. 1629-1645, doi: 10.1111/j.1752-1688.2006.tb06025.x.

Obeidi, A., Kilgour, D.M. and Hipel, K.W. (2009a), "Perceptual stability analysis of a graph model system", IEEE Transactions on Systems, Man, and Cybernetics, Part A, Systems and Humans, Vol. 39 No. 5, pp. 993-1006, doi: 10.1109/TSMCA.2009.2020686.

Obeidi, A., Kilgour, D.M. and Hipel, K.W. (2009b), "Perceptual graph model systems”, Group Decision and Negotiation, Vol. 18 No. 3, pp. 261-277, doi: 10.1007/s10726-008-9154-6.

Philpot, S., Johnson, P.A. and Hipel, K.W. (2017), "Analysis of a brownfield management conflict in Canada”, Hydrological Research Letters, Vol. 11 No. 3, pp. 141-148, doi: 10.3178/hrl.11.141. 
Rego, L.C. and dos Santos, A.M. (2015), "Probabilistic preferences in the graph model for conflict resolution”, IEEE Transactions on Systems, Man, and Cybernetics: Systems, Vol. 45 No. 4, pp. 595-608, doi: 10.1109/tsmc.2014.2379626.

Silva, M.M., Kilgour, D.M., Hipel, K.W. and Costa, A.P.C.S. (2017), "Probabilistic composition of preferences in the graph model with application to the new Recife project", Journal of Legal Affairs and Dispute Resolution in Engineering and Construction, Vol. 9 No. 3, pp. 05017004-105017004-13, doi: 10.1061/(asce)la.1943-4170.0000235.

Takahashi, M.A., Fraser, N.M. and Hipel, K.W. (1984), “A procedure for analysing hypergames”, European Journal of Operational Research, Vol. 18 No. 1, pp. 111-122, doi: 10.1016/0377-2217(84)90268-6.

UNCTAD (2017), Review of Maritime Transport, United Nations Conference on Trade and Development, United Nations, Geneva.

Wang, M. and Hipel, K.W. (2009), "Misperceptions and hypergame models of conflict", in Hipel, K.W. (Ed.), Conflict Resolution, Encyclopedia of Life Support Systems (EOLSS), Vol II, EOLSS Publishers, Oxford, pp. 167-188, available at: www.eolss.net

Wang, M., Hipel, K.W. and Fraser, N.M. (1988), "Modelling misperceptions in games", Behavioural Science, Vol. 33 No. 3, pp. 207-223, doi: 10.1002/bs.3830330305.

Wang, M., Hipel, K.W. and Fraser, N.M. (1989), "Solution concepts in hypergames", Applied Mathematics and Computation, Vol. 34 No. 3, pp. 147-171, doi: 10.1016/0096-3003(89)90102-1.

Xiao, Y., Hipel, K.W. and Fang, L. (2015), "Strategic investigation of the Jackpine mine expansion dispute in the Alberta oil sands", International Journal of Decision Support System Technology, Vol. 7 No. 1, pp. 50-62, doi: 10.4018/ijdsst.2015010104.

Xu, H., Hipel, K.W., Kilgour, D.M. and Fang, L. (2018), Conflict Resolution Using the Graph Model: Strategic Interactions in Competition and Cooperation, ISBN: 978-3-319-77669-9, Springer, Cham, 436pp.

Yousefi, S., Hipel, K.W. and Hegazy, T. (2010a), "Attitude-based strategic negotiation for conflict management in construction projects", Project Management Journal, Vol. 41 No. 4, pp. 99-107, doi: $10.1002 / \mathrm{pmj} .20193$.

Yousefi, S., Hipel, K.W. and Hegazy, T. (2010b), "Attitude-based negotiation methodology for the management of construction disputes", Journal of Management in Engineering, Vol. 26 No. 3, pp. 114-122, doi: 10.1061/(ASCE)ME.1943-5479.0000013.

Yousefi, S., Hipel, K.W. and Hegazy, T. (2010c), "Considering attitudes in strategic negotiation over brownfield disputes", ASCE Journal of Legal Affairs and Dispute Resolution in Engineering and Construction, Vol. 2 No. 4, pp. 1-10, doi: 10.1061/(ASCE)LA.1943-4170.0000034.

Yousefi, S., Hipel, K.W. and Hegazy, T. (2011), "Optimum compromise among environmental dispute issues using attitude-based negotiation”, Canadian Journal of Civil Engineering, Vol. 38 No. 2, pp. 184-190, doi: 10.1139/L10-125.

Yu, J., Hipel, K.W., Kilgour, D.M. and Zhao, M. (2016), "Option prioritization for unknown preference", Journal of Systems Science and Systems Engineering, Vol. 25 No. 1, pp. 39-61, doi: 10.1007/s11518015-5282-0.

Zhao, S. and $\mathrm{Xu}, \mathrm{H}$. (2017), "Grey option prioritization for the graph model for conflict resolution", Journal of Grey System, Vol. 29 No. 3, pp. 14-25.

Zhu, Z., Kilgour, D.M. and Hipel, K.W. (2018), "A new approach to coalition analysis within the graph model”, IEEE Transactions on Systems, Man, and Cybernetics: Systems, 11pp., doi: 10.1109/ TSMC.2018.2811402.

\section{Corresponding author}

Keith W. Hipel can be contacted at: kwhipel@uwaterloo.ca

For instructions on how to order reprints of this article, please visit our website:

www.emeraldgrouppublishing.com/licensing/reprints.htm

Or contact us for further details: permissions@emeraldinsight.com 